\title{
AKTIVITAS BELAJAR MATEMATIKA SISWA PADA PENERAPAN MODEL PEMBELAJARAN KOOPERATIF TIPE TEAM-GAME-TOURNAMENT (TGT) BERBANTUAN MEDIA POWERPOINT
}

\author{
Rizka Furqany ${ }^{1}$, Effie Efrida Muchlis ${ }^{2}$, Hanifah $^{3}$ \\ ${ }^{1,3}$ Program Studi Pendidikan Matematika JPMIPA FKIP Universitas Bengkulu \\ ${ }^{2}$ Program Studi S-2 Pendidikan Dasar FKIP Universitas Bengkulu \\ ${ }^{1}$ rizkafurqany06@gmail.com, ${ }^{2}$ effie_efrida@yahoo.com, ${ }^{3}$ ifahzen@gmail.com
}

\begin{abstract}
Abstrak
Penelitian ini bertujuan untuk meningkatkan aktivitas belajar siswa dengan cara menerapkan Model Pembelajaran Kooperatif Tipe TGT berbantuan Powerpoint pada materi segitiga dan segiempat. Jenis penelitian yang dilaksanakan adalah Penelitian Tindakan Kelas (PTK) dengan teknik pengumpulan data melalui lembar observasi aktivitas siswa. Subjek dalam penelitian ini adalah siswa kelas VII F MTs Negeri 2 Kota Bengkulu. Hasil penelitian ini menunjukkan bahwa penerapan Model Pembelajaran Kooperatif Tipe TGT berbantuan Powerpoint dapat meningkatkan aktivitas dan hasil belajar matematika siswa. Peningkatan aktivitas siswa dapat dilihat dari skor rata-rata aktivitas siswa dari siklus I hingga siklus III yaitu: 19,6; 22,25; 25,5 .
\end{abstract}

Kata Kunci: aktivitas siswa, model pembelajaran kooperatif, powerpoint, team games turnamen.

\begin{abstract}
The aim of this research is to know the application's Co-operative Learning Team Games Turnamen with Powerpoint Assisted in order to improve activity on the material of Triangle and quadrilateral. The type of this research is classroom action researh with collecting data through student's observation forms. The subject of this research is students grade VII F MTsN Bengkulu City. The results of this research shows that the application of Co-operative Learning Team Games Turnamen with Powerpoint Assisted can improve activity and student's test result in Mathematics. Improving student activity can be seen from the average score of the first cycle to third cycle, namely: 19,6; 22,$25 ; 25,5$.
\end{abstract}

Keywords: co-operative learning, student's activities, powerpoint, team games turnamen.

\section{PENDAHULUAN}

Rancangan pembelajaran yang mencerminkan kegiatan belajar secara aktif perlu didukung oleh kemampuan guru memfasilitasi kegiatan belajar siswa selama proses pembelajaran berlangsung. Mengaktifkan kegiatan belajar siswa berarti menuntut kreativitas dan kemampuan guru dalam merancang dan melaksanakan kegiatan pembelajaran. Kualitas pembelajaran merupakan tingkat pencapain tujuan pembelajaran. Depdiknas (2004: 7-10) menyatakan bahwa indikator kualitas pembelajaran dapat dilihat sebagai berikut: perilaku pembelajaran pendidik, perilaku dan dampak belajar siswa, iklim pembelajaran, materi pembelajaran yang berkualitas, kualitas media pembelajaran, sistem pembelajaran.
Dari hasil observasi yang dilakukan pada proses pembelajaran di kelas VII F MTs Negeri 2 Kota Bengkulu pada tanggal 15 Maret 2017, khususnya pelajaran Matematika cenderung didominasi oleh guru, hal tersebut dikarenakan guru menggunakan metode pembelajaran konvensioanal yang mengandalkan metode ceramah di depan kelas. Metode konvensional yang digunakan pada saat mengajar hanya menitikberatkan pada kreatifitas guru sedangkan siswa kurang tertarik dengan cara guru menyampaikan materi. Dari hasil pengamatan diperoleh 5 siswa $(17,8 \%)$ dari 28 siswa tidak memperhatikan guru ketika proses pembelajaran berlangsung, siswa mengobrol diluar topik pembelajaran berjumlah 7 siswa (25\%) dari 28 siswa, siswa cenderung 
pasif berjumlah 15 siswa (53\%) dari 28 siswa, dan sebagian siswa tidak membawa buku pelajaran berjumlah $3 \operatorname{siswa}(10,7 \%)$ dari 28 siswa.

Banyak siswa yang berangggapan bahwa pelajaran matematika sebagai pelajaran yang paling susah dan membosankan karena sering kali guru menciptakan suasana pembelajaran yang tidak menyenangkan bagi siswa. Guru banyak memberikan penjelasan tanpa memperhatikan siswa, apakah sudah paham atau belum.

Salah satu satu strategi yang dapat meningkatkan kerjasama antar siswa adalah Cooperatif Learning. Dengan menggunakan model pembelajaran kooperatif Teams Games Tournament (TGT). Model pembelajaran TGT adalah salah satu tipe atau model pembelajaran kooperatif yang dapat diterapkan pada pembelajaran matematika, melibatkan aktivitas seluruh siswa tanpa harus ada perbedaan status, melibatkan peran siswa sebagai tutor sebaya dan mengandung unsur permainan serta reinforcement.

Menurut Suprijono (2011: 54) Pembelajaran kooperatif adalah konsep yang lebih luas meliputi semua jenis kerja kelompok termasuk bentuk-bentuk yang dipimpinoleh guru atau diarahkan oleh guru. Secara umum pembelajaran kooperatif dianggap lebih diarahkan oleh guru, dimana guru menetapkan tugas dan pertanyaan-pertanyaan serta menyediakan bahan-bahan informasi yang dirancang untuk membantu peserta didik menyelesaikan masalah yang dimaksud. Salah satu bentuk pembelajaran kooperatif yang dipilh peneliti adalah TGT (Team Games Tournament). Model pembelajaran TGT (Team Games Tournament) dipilih peneliti karena model pembelajaran ini adalah salah satu model pembelajaran kooperatif yang mudah diterapkan dan mengandung unsur permainan sehingga memungkinkan siswa untuk belajar lebih rileks, menumbuhkan tanggung jawab, serta kerja sama antar teman (Hamdani, 2011 : 92).

Penggunaan media juga mempengaruhi aktifitas dan perkembangan siswa dalam menerima materi pembelajaran yang disampaikan guru. Salah satu media yang dapat digunakan dalam materi segitiga dan segiempat adalah powerpoint. Media pembelajaran adalah segala sesuatu yang dapat digunakan untuk menyalurkan pesan dari pengirim ke penerima sehingga merangsang pikiran, perasaan, perhatian dan minat serta kemauan peserta didik sedemikian rupa sehingga proses belajar terjadi dalam rangka mencapai tujuan pembelajaran secara efektif (Sukiman, 2012: 29). Melalui media tersebut, maka siswa akan lebih termotivasi dalam pembelajaran Matematika dan proses pembelajaran akan berjalan lebih efektif dan menyenangkan.

Menurut Sukiman Penggunaan media Powerpoint sebagai suatu alternatif pemecahan masalah dianggap paling tepat karena dengan Microsoft Powerpoint ini kita akan dapat merancang dan membuat presentasi yang lebih menarik dan profesional (Sukiman, 2012: 213). Pemanfaatan media presentasi ini dapat digunakan oleh pendidik maupun untuk mepresentasikan materi pembelajaran ataupun tugas-tugas yang akan diberikan. Sehingga siswa dalam Pembelajaran Matematika pada kelas VIIF Mts Negeri 2 Kota Bengkulu dalam materi Segitiga dan Segiempat akan lebih tertarik dan temotivasi untuk fokus dalam pembelajaran dan pemehaman siswa akan meningkat.

Rumusan masalah pada penelitian ini adalah bagaimana menerapkan model pembelajaran kooperatif tipe Teams-GamesTournament (TGT) berbantuan media Powerpoint untuk meningkatkan aktivitas belajar matematika siswa di kelas VII F MTs Negeri 2 Kota Bengkulu .

\section{METODE PENELITIAN}

Sesuai dengan permasalahan dan tujuan di atas maka Jenis penelitian ini adalah Penelitian Tindakan Kelas (PTK) atau Classroom Action Research. Haryono (2015:25) mendefinisikan pengertian PTK sebagai "suatu bentuk penelitian yang bersifat reflektif dengan melakukan tindakan-tindakan tertentu agar dapat memperbaiki dan atau meningkatkan praktek-praktek pembelajaran dikelas secara lebih profesional". Subjek dalam penelitian ini adalah siswa Kelas VII F MTs 
Negeri 2 Kota Bengkulu dengan jumlah 28 siswa.

Model penelitian tindakan kelas memiliki empat tahapan dilalui yaitu perencanaan (Planning), pelaksanaan Tindakan (Acting). Pengamatan (Observing), dan refleksi (Reflecting).

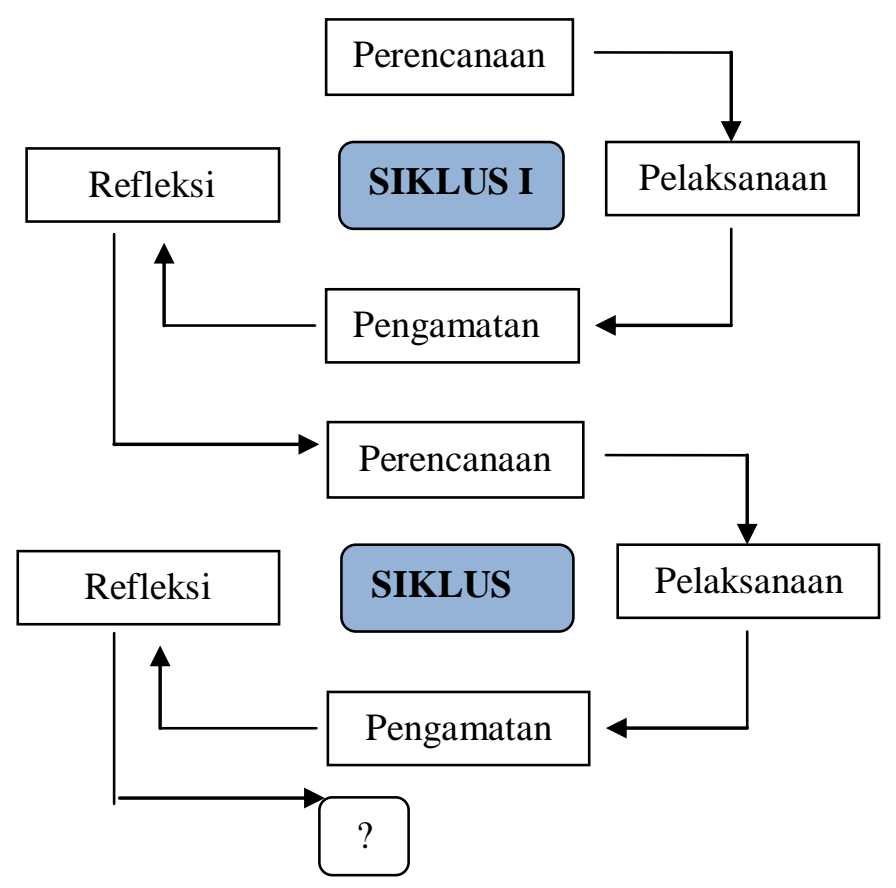

\section{Gambar 1. Siklus Penelitian Tindakan Kelas dalam Arikunto (2012:16)}

Dalam penelitian ini, instrumen yang digunakan adalah lembar observasi. Lembar observasi yang digunakan adalah lembar observasi aktivitas siswa yang berupa pengamatan terhadap aktivitas siswa selama proses belajar mengajar berlangsung.

Data yang diperoleh dari hasil observasi akan dianalisis secara deskriptif kualitatif. Lembar observasi aktivitas siswa diolah dengan menggunakan persamaan berikut ini :

Skor rata - rata tiap siklus

$$
=\frac{\text { jumlah skor }}{\text { jumlah pengamat }}
$$

(Modifikasi Sudjana, 2009: 32-33)

Kriteria yang digunakan adalah Baik (B), Cukup (C), dan kurang (K)
Tabel 1 Kriteria penilaian untuk lembar observasi aktivitas siswa

\begin{tabular}{|c|c|c|c|}
\hline No & $\begin{array}{c}\text { Kriteria } \\
\text { Penilaian }\end{array}$ & Notasi & Skor \\
\hline 1 & Kurang & K & 1 \\
\hline 2 & Cukup & C & 2 \\
\hline 3 & Baik & B & 3 \\
\hline
\end{tabular}

(Modifikasi Sudjana, 2009)

kisaran skor penilaian untuk lembar observasi aktivitas siswa adalah sebagai berikut :

\section{Tabel 2 Kriteria Skor Pengamatan untuk} Lembar Observasi Aktivitas Siswa

\begin{tabular}{|c|c|}
\hline Kategori Penilaian & Kisaran Skor \\
\hline Tidak Aktif & $8 \leq x \leq 14$ \\
\hline Cukup Aktif & $14<x \leq 21$ \\
\hline Aktif & $21<x \leq 28$ \\
\hline
\end{tabular}

(Modifikasi Sudjana, 2009)

Analisis ini dilakukan pada saat tahapan refleksi. Hasil analisis ini digunakan sebagai bahan refleksi untuk melakukan perencanaan lanjut dalam siklus selanjutnya.

Berdasarkan tabel kriteria penilaian lembar observasi dan kriteria skor pengamatan lembar observasi dapat disimpulkan kriteria dan indikator keberhasilan tindakan penelitian adalah hasil aktivitas siswa mencapai kriteria baik yaitu berada pada interval 21-28 maka siswa dikatakan aktif, sehingga guru sudah dikatakan menerapkan model kooperatif tipe Teams Games Tournament (TGT) dengan maksimal.

\section{HASIL DAN PEMBAHASAN}

Penelitian tindakan kelas dilaksanakan selama tiga siklus. Observasi aktivitas siswa dilakukan oleh dua pengamat. Skor rata-rata dua pengamat menunjukkan bahwa aktivitas siswa mengalami peningkatan disetiap siklusnya. Adapun grafik peningkatan skor rata-rata aktivitas siswa setiap siklus seperti gambar 2. 


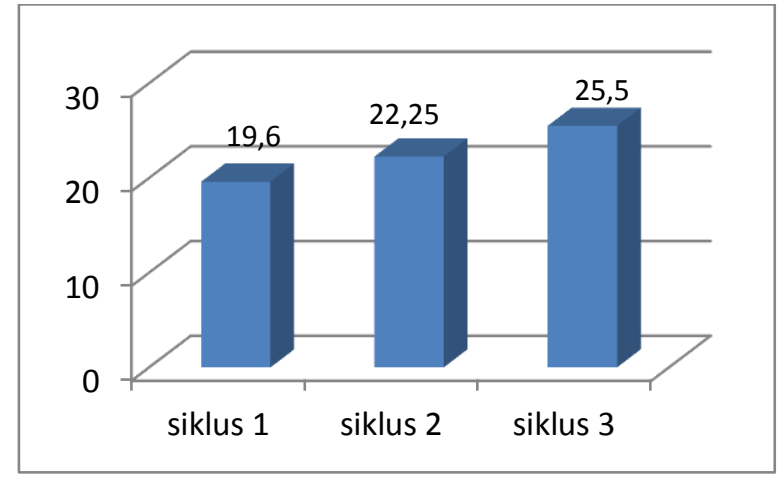

\section{Gambar 2. Grafik Peningkatan rata-rata aktivitas siswa}

Pada siklus I aktivitas yang dilakukan oleh siswa berada pada kriteria Cukup Aktif dengan skor rata-rata 19,6. Penyebab rendahnya aktivitas siswa pada siklus I antara lain disebabkan oleh rendahnyaaktivitas siswa ketika guru menyampaikan materi pembelajaran pada tahap presentasi. Siswa belum berani untuk bertanya ataupun menjawab pertanyaan guru ketika menjelaskan. Pada siklus I aktivitas siswa cenderung pasif serta melakukan kegiatan yang tidak relevan dengan aktivitas pembelajaran, siswa yang serius memperhatikan dan ikut terlibat aktif ketika guru menjelaskan didominasi oleh siswa yang berkemampuan tinggi.

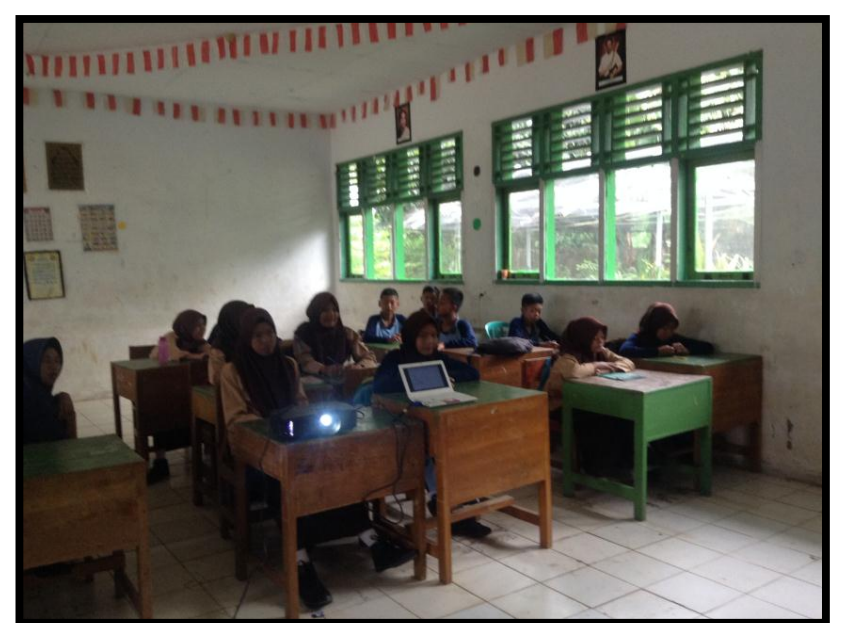

Gambar 3. Keadaan Siswa pada siklus 1 tahap Presentasi

Pada siklus II aktivitas belajar siswa mengalami peningkatan menjadi kriteria aktif dengan skor rata-rata 22,25. Pada tahap Presentasi siswa mulai mengamati penjelasan materi pembelajaran dan ikut terlibat aktif dengan guru.

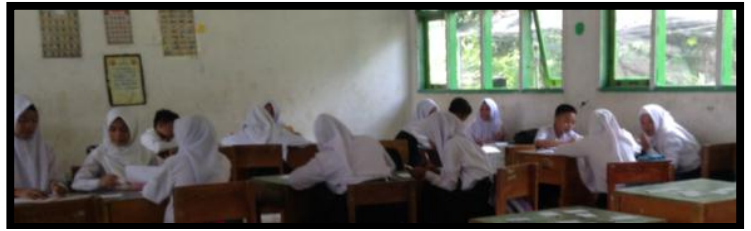

Gambar 4. Keadaan Siswa pada tahap Game Tournament

Pada siklus III aktivitas siswa mengalami peningkatan yang semakin baik. Siswa sudah terbiasa dengan model kooperatif tipe TGT (teams games turnamen). Hal ini dapat terlihat dari peningkatan aktivitas belajar siklus sebelumnya. Siswa mulai terbiasa menyimak materi dengan baik, ikut aktif bertanya dan menanggapi penjelasan dari guru, seperti yang terlihat pada gambar berikut:

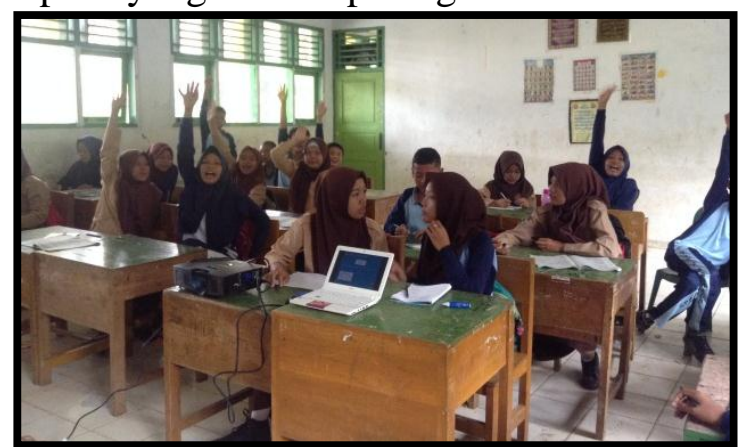

Gambar 5. Siswa aktif pada tahap Presentasi siswa mampu menjawab lembar latihan tanpa bertanya kembali kepada guru, siswa aktif berdiskusi mencocokkan jawaban dengan kunci jawaban yang guru berikan, siswa mulai saling memberikan pemahaman mengenai soalsoal dan materi pelajaran, hal ini terlihat pada gambar berikut:

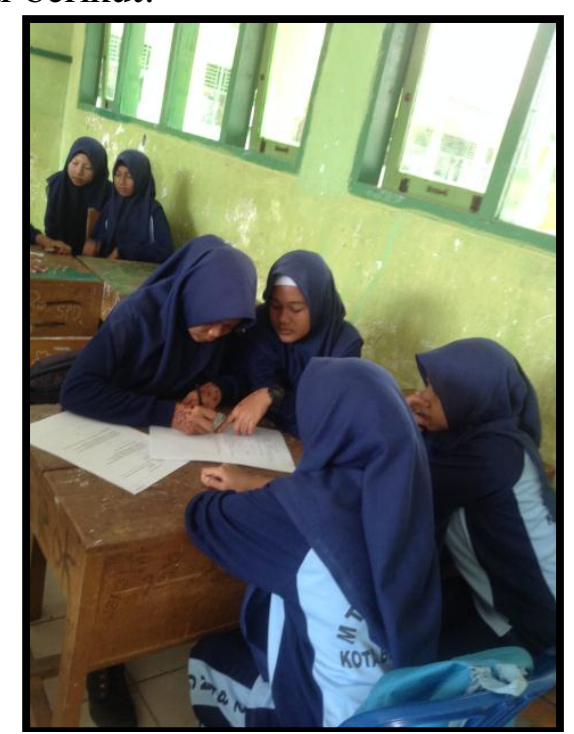

Gambar 6. Siswa Aktif berdiskusi pada tahap Team 
Selain itu siswa juga melakukan game turnamen dan merekognisi poin dengan baik, banyak siswa yang berani dan mengajukan diri untuk memberikan kesimpulan akhir pelajaran. Oleh karena itu, secara umum aktivitas belajar siswa pada siklus III tergolong aktif dan mencapai indikator keberhasilan yakni 25,5.

\section{PENUTUP}

\section{Simpulan}

Berdasarkan penelitian yang telah dilaksanakan dikelas VII F MTsN 2 Kota Bengkulu dapat diambil kesimpulan sebagai berikut :

Penerapan Model Kooperatif tipe Team Game Turnamen (TGT) dapat meningkatkan aktivitas belajar siswa dengan cara Penggunaan media powerpoint pada saat penyampaian materi atau tahap presentasi, agar siswa lebih aktif dan lebih terarah sesuai tujuan pembelajaran, Memberikan lembar latihan yang relevan dengan materi yang disampaikan sebelum membagikan lembar jawaban latihan, Menerapkan sistem poin terhadap jawaban siswa pada game turnamen, Guru memberikan bantuan belajar khusus dan kesempatan lebih, dalam proses pembelajaran kepada siswa yang berkemampuan rendah, Guru menegur siswa yang ribut dan memisahkan siswa yang ribut agar tidak duduk berdekatan, Sebagai bentuk motivasi dan penghargaan guru dan siswa memberikan applause kepada peraih Tim Baik, Tim Sangat Baik, dan Tim Super.

Skor rata-rata pengamatan aktivitas siswa pada siklus 1 adalah 19,6 dengan kriteria cukup aktif, siklus II meningkat pada kriteria aktif dengan skor 22,25 dan siklus III aktivitas siswa tergolong aktif dengan skor 25,5

\section{Saran}

Dari penelitian untuk yang dilakukan peneliti menyarankan berbagai hal sebagai berikut:

a. Guru sebaiknya lebih teliti terhadap urutan perengkingan nilai dan mempertimbangkan kembali siswa yang benar-benar memiliki kemampuan
Sehingga tidak terjadi kesalahan dalam penempatan kelompok belajar yang berpengaruh terhadap pembagian tim turnamen.

b. Sebelum menentukan alat pengukuran yang digunakan oleh siswa, sebaiknya guru memastikan siswa terampil dalam menggunakan alat tersebut.

c. Guru sebaiknya memberikan poin tambahan ketika siswa mampu menjawab pertanyaan yang diberikan guru pada tahap presentasi agar siswa bersemangat mengamati presentasi guru.

d. Sebelum memulai pembelajaran sebaiknya guru mengumumkan kelompok belajar dan kelompok turnamen kepada siswa agar siswa dapat lebih tertib ketika berkumpul pada kelompok belajar maupun kelompok turnamen.

e. Sebaiknya guru lebih memperhatikan meja turnamen kategori kemampuan rendah, karena pada kategori kemampuan ini sering melakukan kecurangan. Disarankan untuk meletakkan posisi meja turnamen kategori kemampuan rendah di paling depan, atau berada didekat pengamat.

\section{DAFTAR PUSTAKA}

Agus, Suprijono. 2011. Model Pembelajaran Kooperatif. Jakarta: Bumi Aksara.

Arikunto, Suharsimi.(2012). Penelitian

Tindakan Kelas. Jakarta: Bumi Aksara

Depdiknas. 2004. Panduan Penyusunan

Kurikulum Tingkat Satuan Pendidikan Jenjang. Pendidikan Dasar dan Menengah, Standar Isi, Standar Kelulusan. Jakarta : Depdiknas.

Hamdani. 2011. Strategi Belajar Mengajar. Bandung : Pustaka Setia.

Haryono.(2005).Bimbingan Teknik Menulis Penelitian Tindakan Kelas. Yogyakarta: Amara Books.

Sudjana, Nana.(2009). Penilaian Hasil Proses Belajar Mengajar. Bandung: Remaja Rosdakarya

Sukiman. 2012. Pengembangan Media Pembelajaran. Yogyakarta : Pustaka Insan. 